Journal of the Scholarship of Teaching and Learning, Vol. 21, No. 4, December 2021, pp. 164-176. doi: 10.14434/josotl.v21i4.32673

\title{
Case Study: Partnering Intercultural Communication Students with Campus Co-Cultural Student Groups to Develop Intercultural Competence, Allyship, and Curiosity
}

\author{
Rebecca A. Kuehl \\ South Dakota State University
}

\begin{abstract}
The question I analyze in this case study is how might one use civic engagement to foster campus/community relationships in this polarized era? I describe a teaching challenge in intercultural communication. Students have consistently reported that they arrive to this university from rural, majority-White communities where they have not experienced opportunities to communicate with culturally diverse groups. To address this challenge, I developed a semester-long assignment that provides a structured partnership between students in my Intercultural Communication course and campus co-cultural student groups. To assess this assignment's benefit to the pedagogy surrounding polarization across cultural differences, I qualitatively analyzed themes in students' reflection papers $(N=128$ papers) from the last five sections of the course (2016-2020). Students addressed how these partnerships helped them develop (1) intercultural competence, (2) acceptance or appreciation through allyship, and (3) curiosity about other cultures. I conclude with implications, including how colleagues might use this assignment in other rural, land-grant public university settings.
\end{abstract}

Keywords: intercultural communication, intercultural competence, White allyship, campus/community partnerships, intergroup dialogue.

Political partisanship "continues to be the dividing line in the American public's political attitudes" (Pew Research Center, 2019). University educators face this polarized public in the classroom, which includes the challenge of having students communicate with culturally diverse people, including across cultural differences. Cultural differences include but are not limited to differences across sex, race/ethnicity, gender, sexual orientation, language, religion, nation of origin, ability, and political affiliation (Sorrells, 2016). One course that addresses this teaching challenge of polarization across cultural differences is Intercultural Communication.

The question I analyze in this case study is how might one use civic engagement to foster campus/community relationships in this polarized era? In what follows, I describe a teaching situation I face as a White, cisgender female professor in a predominantly White institution (PWI) that is also a land-grant public university in the midwestern United States. I teach Intercultural Communication, where most students report that they arrive to this university from rural, majority White, conservative, and Christian communities where most have not interacted with culturally diverse communities. This can often be the case for students taking Intercultural Communication, where depending on geographical context, students may enter such a course having never before communicated with someone from a different country or culture (Heinz, 2004).

To address this teaching challenge, I developed a semester-long assignment that provides a structured partnership between groups of students taking Intercultural Communication and campus co-cultural student groups (see Appendix). Early in the semester, I contact colleagues who serve as advisors to these co-cultural groups, asking for their voluntary partnership and noting that Intercultural Communication students will learn about and practice ethical communication. Students work in class groups to research intercultural communication concepts, conduct interviews with 
members of their partnered co-cultural group, and present to the rest of the class about how that cocultural group negotiates their identity at a PWI and in U.S. culture.

To assess this assignment's benefit to the pedagogy surrounding polarization across cultural differences, I analyzed themes in students' reflection papers $(N=128$ papers $)$ from the last five sections of the course (2016-2020). Students addressed how these partnerships helped them develop (1) intercultural competence, (2) acceptance or appreciation through allyship, and (3) curiosity about other cultures. I conclude with implications, including the utility of the assignment in other rural, landgrant public university settings.

\section{Teaching Challenge: Fostering Campus/Community Partnerships in a Polarized Era}

The teaching challenge explored in this case study is how to address students' polarization across cultural differences, including political affiliation. My positionality includes identifying as a White, cisgender female, U.S.-born professor in a PWI that is a land-grant public university in the midwestern United States. Students come to the Intercultural Communication class culturally polarized and hesitant about how to interact with those who are different from them. This course is an upper-level, required course for undergraduate communication studies majors and a required course for undergraduate global studies minors.

At the beginning of the course, students write a positionality paper, in which they explain two to three facets of their own cultural identity (e.g., race/ethnicity, sex, gender identity, socioeconomic status, ability, etc.) and how that part of their identity positions them with privilege (or not) in relation to other co-cultural groups in the United States. In these papers, most students have reported that they arrived to this university from rural, majority White, politically conservative, Christian, U.S. communities where they have not experienced many opportunities to communicate with culturally diverse groups. Heinz (2004) explained that many students may not have direct experience interacting with someone from another country or culture prior to taking such a course. This phenomenon serves as one reason that grounds a movement to globalize undergraduate education, including increasing opportunities for U.S.-born students to interact with international or other culturally diverse students during their university education (Driskill, 2007; Kuehl \& Hungerford, 2017). To deepen learning, students should experience both learning processes that are culturally natural to them and some that are culturally new (Chávez \& Longerbeam, 2016).

However, in helping students learn in culturally new ways, one must be mindful of the constraints of performative White allyship, especially given that a majority of the students in this course typically self-identify as White. Hernández (2020) wrote: "When performative white allyship is represented by centering one's self or expecting recognition, this can result in the perpetuation of white saviorism and white martyrdom that further recenters whiteness" (p. 150). White allyship must move beyond a self-recognition of privilege through silence (Cross, 2021; Desnoyers-Colas, 2021). Instead, White allyship must involve taking risks, calling out inequities, and dismantling systems of exclusion that disadvantage those who do not identify as White (Desnoyers-Colas, 2021; Hernández, 2020; Hesford, 2021).

Recognizing the constraints of performative White allyship, I now turn to the geographical and political context of this case study. This context shows the difficulties I face in teaching content related to cultural diversity in this midwestern U.S. state. Despite efforts to globalize undergraduate education on a national level, the state where this university is located presents unique challenges to creating campus/community partnerships between Intercultural Communication students and culturally diverse students. Efforts toward "intellectual diversity" in this state have been effective, serving as a model in a national conversation that reflects political polarization in the United States when it comes to freedom of speech and political affiliation in higher education (Hess, 2019).

Journal of the Scholarship of Teaching and Learning, Vol. 21, No. 4, December 2021. josotl.indiana.edu 
Specifically, these intellectual diversity laws are a potential barrier to globalization and open discussions of diversity, equity, and inclusion in the university curriculum. A series of state laws have been some of the first in the country to address intellectual diversity on state college and university campuses (Ellis, 2019; Foundation for Individual Rights in Education [FIRE], 2019; Hess, 2019). As a result, some citizens are concerned about the future of the state's diversity efforts.

The chilling effect of these intellectual diversity laws on university educators remains unclear; however, in discussions with other faculty who teach content related to diversity, equity, and inclusion, this climate has made it difficult to discuss concepts such as positionality of identity, privilege, and social justice. One state law "requires public institutions of higher education to submit an annual report to the Governor and state legislature detailing actions that promoted or burdened free expression and intellectual diversity" (FIRE, 2019). Because of this legislative tracking of intellectual diversity in institutions of higher education in the state, some faculty are tentative about teaching the aforementioned concepts that are perceived to be politically liberal in the United States.

Given this context of political polarization in the state and of students who take this course, one approach is to foster campus/community partnerships to enhance students' civic engagement and create dialogue with culturally diverse groups. Intergroup dialogues can improve students' relationships and strengthen campus communities (Cross, 2021; Parker et al., 2011). Cross (2021) explained that intergroup dialogues facilitate having uncomfortable or difficult conversations about race and gender in the classroom. Community-based participatory research partnerships, which often include campus/community partnerships, can foster relationships across cultural differences (Kuehl et al., 2020). Exposure to people who are culturally different from oneself cultivates empathy and increases understanding of people's diverse lived experiences. Additionally, intercultural partnerships enhance campus and community exposure to intercultural topics, including managing cultural differences (Driskill, 2007). In-depth international or intercultural partnerships are effective when students analyze their intercultural communication, evaluating intercultural competence and the circulation of stereotypes (Heinz, 2004). Using this knowledge about campus/community intercultural partnerships, I developed a semester-long assignment as one solution to the teaching challenge of polarization across cultural differences in Intercultural Communication.

\section{Solution to This Teaching Challenge: Partnering With Campus Co-Cultural Student Groups}

Over time, I developed and adjusted a semester-long assignment that provides a structured partnership between groups of Intercultural Communication students and campus co-cultural student groups (see Appendix 1). In the time period under review for analysis (2016-2020), students worked with many co-cultural groups, including the Black Student Alliance, African Students' Association, Indian Students' Association, Nepalese Students' Association, Feminist Equality Movement, Gender \& Sexualities Alliance, International Relations Council, Latin American Students' Association, American Indian Students' Association, and the American Sign Language Club.

Early in each semester, before students select their class groups or choice of co-cultural groups with whom to develop a campus/community partnership, I email colleagues who serve as advisors to these co-cultural groups. In that email, I ask advisors for their voluntary partnership during the semester, noting that students will learn and practice ethical intercultural communication. In every semester I have taught the course, advisors have been supportive and have sent on the message to their co-cultural student group leaders. Student leaders then communicate with me about whether their group wants to participate. Typically, student leaders are eager to partner with the Intercultural Communication students, partially because one purpose of these campus co-cultural student groups is to educate others about their members' culture or identity.

Journal of the Scholarship of Teaching and Learning, Vol. 21, No. 4, December 2021. josotl.indiana.edu 
Once I have secured agreement from the co-cultural groups that they want to participate in a partnership with the Intercultural Communication students, I ask the Intercultural Communication students to list three campus co-cultural student groups that they do not know much about and/or would like to learn more about. I then assign all of the students to their class groups on the basis of this interest. The course has usually enrolled 30 students every semester, so there are five to six class groups partnered with the co-cultural groups.

The first stage of the semester-long assignment is for class groups to conduct research about intercultural communication concepts and their partnered campus co-cultural student group. As a class group, they are required to have at least 10 peer-reviewed sources from the communication literature that shape their understanding of this group or culture. This research also grounds the development of the interview questions they will use when they conduct two 30-minute structured interviews with members of their partnered co-cultural group. The class groups work on their interview questions in class during different class sessions, developing a draft of the interview guide that I review in the middle of the semester (roughly Week 8). Once I review and provide revisions for the guide, the class group then incorporates those revisions and shares the final guide with me to obtain my approval before conducting interviews.

In the second stage of the assignment, once class groups have their final interview guide, they contact the leaders of their partnered co-cultural groups to schedule and conduct the two interviews with members of that co-cultural group. These interviews typically take place during Weeks 10-12 of the 16-week semester. I ask students to audio or video record the interviews (only after first obtaining participants' permission). If they or the participants choose not to record, they turn in their notes that provide a transcription of the interview questions and answers.

In the final stage of the project, class groups present to the rest of the class about how their partnered co-cultural group negotiates their identity at a PWI and in U.S. culture. Before the students present, I send out the class presentation dates to the co-cultural groups so that they can attend. In the time period under analysis (2016-2020), three different co-cultural groups attended students' class presentations; they asked questions of their class group partners following the presentation and answered questions about their co-cultural group's experiences of navigating their cultural identity at a PWI. For example, one class discussion focused on how cultural space communicates significance, involving a discussion about the location of the Multicultural Center in the basement of the University Student Union, and what that choice of cultural space communicates to the larger community. In these final group presentations, students analyze their partnered co-cultural group's experiences through five intercultural communication concepts. To support that analysis, students use evidence from peer-reviewed research and interviews with members of the co-cultural groups. Each class group has an entire class period (50 minutes) in which to present, and every class member must speak.

I changed the assignment periodically during 2016-2020, but the three major stages of the project (research, interviews, presentation) remained consistent. For example, I used to ask Intercultural Communication students to initiate contact with student leaders on their own. I have found that by having the instructor initiate first contact with advisors, it adds a layer of credibility and safety in asking campus co-cultural groups to partner with the class.

I also used to let students conduct interviews without my approval of their revised interview guide. I have found that by setting a firm midsemester deadline for the interview guide and the requirement of my approval, students are better prepared with their interview questions and have more time to conduct interviews. I also set aside a few class periods for students to work on the interview guide in class and to be able to ask questions about their five targeted intercultural communication concepts. This helped students increase their confidence in conducting interviews.

Finally, in fall 2020 I reduced the requirement of two interviews to one interview that students conducted on Zoom, because of the COVID-19 pandemic. During that semester, many students had

Journal of the Scholarship of Teaching and Learning, Vol. 21, No. 4, December 2021. josotl.indiana.edu 
a mix of online, hybrid, and face-to-face classes at the university. As a result, students faced difficulties in arranging meeting times to conduct the interviews.

Although this assignment went well for most of the partnerships during the time period of analysis, some partnerships faced difficulties. For example, before I added the layer of the instructor initially contacting co-cultural group advisors, one class group struggled to contact the leaders of the co-cultural group with whom they wanted to partner. They ended up changing to a different cocultural group later in the semester, because they never heard back from the leaders of the initial cocultural group. I have not measured reciprocal learning between the class and co-cultural groups; however, this could be a valuable tool to ensure performative White allyship is not functioning as a burden on the co-cultural student groups. I next turn to the analysis of students' learning through their reflection papers.

\section{Qualitative Analysis of Intercultural Communication Students' Reflection Papers}

To measure the effectiveness of this teaching solution, I used qualitative inductive analysis (Braun \& Clarke, 2006) to determine themes from students' reflection papers. Before conducting the analysis, I obtained approval from the university's Institutional Review Board: IRB-2105007-EXM. The sample included $N=128$ student reflection papers from the sections I taught in spring 2016, fall 2016 (honors section), fall 2017, fall 2019, and fall 2020. I obtained papers from the online Desire2Learn Dropbox in each course. I was on sabbatical leave when the course was taught in fall 2018, so I did not have access to those papers.

As the sole instructor for all five sections of Intercultural Communication, I have a unique standpoint in analyzing these students' papers. I monitored the progress of students' class groups throughout the semester in which they took the class. The prompt for the reflection paper included the following: (1) Offer an explanation of what you have learned from the final group project and this course; (2) articulate how this course has shaped the way you look at the world and your understanding of your own cultural identity, especially in comparison to your initial positionality paper; and (3) address how the course has affected the way you interact with diverse cultures, and the importance of this class for future intercultural communication interactions (could include interpersonal, work/career, family contexts, etc.).

I used inductive analysis in determining themes. Braun and Clarke (2006) defined an inductive approach as a method in which the themes are strongly linked to the data themselves. For this case study, I focused on themes that emerged from students' answers to the first and final prompts of the reflection paper: what they learned from the final group project and how it affected how they interact with diverse cultures. The following themes emerged from the analysis: (1) intercultural competence; (2) acceptance or appreciation through allyship; and (3) curiosity about other cultures. A vast majority of students' reflections were positive. I communicated to students that the reflection papers would be graded on the basis of following directions and not because they praised the course. However, students might have positively slanted their reflections because of a perceived need to affirm their instructor who ultimately graded their work in the class.

\section{Intercultural Competence}

The first theme was intercultural competence, which is defined as "the knowledge, attitudes, and skills needed to engage effectively in intercultural situations" (Sorrells, 2016, p. 260). Students first discussed how the final group project increased their understanding of other cultures and how to adapt and communicate given that understanding. Second, students wrote about how that understanding enabled them to create dialogue and communicate across differences, directly addressing the teaching

Journal of the Scholarship of Teaching and Learning, Vol. 21, No. 4, December 2021. josotl.indiana.edu 
challenge. Finally, students explained that this intercultural competence allowed them to communicate with others such that they avoided disseminating negative stereotypes or misconceptions of other cultures.

Understanding other cultures and adapting communication. Students first discussed intercultural competence through an awareness of how the final group project increased their understanding of other cultures. In turn, that understanding allowed them to adapt their communication. One student wrote that "we need to have an understanding at how our communication might change based on who we are talking to." This adaptation of communication based on knowledge of cultures is part of intercultural competence (Sorrells, 2016). One student even used the metaphor of "bridging" cultural gaps through adaptation: "Not only did I learn about other cultures, I learned how to better bridge the gap between myself and them." Another student explicitly mentioned accommodating for others: "Either way I need to understand the differences between their culture and my own and make a conscious effort to accommodate for that in our communication." Understanding other cultures through partnerships with co-cultural groups allowed students to reflect on how they could then accommodate or adapt for cultural differences in their interactions.

Intercultural competence also emerged through an emphasis on increasing their knowledge of other cultural groups through understanding. One student commented:

By contacting another cultural group on campus, I was able to broaden my understanding of the circumstances and culture the Latin American students have on [sic] both on and offcampus. This has given me more knowledge about a culture I didn't fully know about or comprehend.

Because many students enter this class without a background of interacting with culturally diverse groups (Heinz, 2004), this increasing of understanding through accumulating knowledge of other cultures is an important marker of intercultural competence. One student wrote about using intercultural competence after college: "As I move on with my life past college, I will continue to meet and build relationships with individuals that do not have the same cultural beliefs, values, or norms as I do." This awareness of others' cultural differences and how that affects relationships and communication reflects intercultural competence (Sorrells, 2016).

Creating dialogue and communicating across differences. Students also wrote about intercultural competence through discussing how these campus/community partnerships enabled them to create dialogue and communicate across differences, which directly addresses the teaching challenge of polarization across cultural differences. One student wrote: "To be aware of your own culture and others is of the utmost importance and we should be engaging in dialogue with individuals from diverse cultures." This student connected an awareness of their own and others' cultures to start a dialogue. Another student connected this ability to communicate across differences to their learning from the final group project: "However, learning about how to recognize, be open-minded, and accepting of different cultural identities, is what I needed to enhance conversations such as the final [group] project." Starting conversations with co-cultural groups was not always easy. Another student described how the partnership pushed them "to think outside of my own comfort zone" to communicate across differences. The final group project gave students an opportunity to practice intercultural competence in a structured setting through a campus/community partnership.

Communicating with others to avoid negative stereotypes or misconceptions. Intercultural competence also emerged through how students said they would communicate with others to avoid negative stereotypes and misconceptions about other cultural groups. One student wrote that by interacting with a co-cultural student group, that experience helped them consider how to "avoid any negative misconceptions" that might happen without an awareness of how different cultures interact. Students

Journal of the Scholarship of Teaching and Learning, Vol. 21, No. 4, December 2021. josotl.indiana.edu 
reflected on how intercultural competence could help them avoid stereotyping culturally diverse groups. One student wrote:

While recognizing these differences [between myself and others], I need to make sure to make note of my own biases and ignore any preconceived stereotypes that I may already have in my mind. This will help me to better talk across any differences I may have with those I encounter on the job.

Overall, students recognized the importance of intercultural competence and how it would enable them to have a successful future, in personal relationships and the workplace. The final group project enabled students to practice communicating across differences and to enact intercultural competence in a structured campus/community partnership.

\section{Acceptance or Appreciation Through Allyship}

The second theme was acceptance or appreciation of other cultures through developing allyship. Students used language such as "acceptance," "appreciation," or "connection" when discussing their campus/community partnership. Students also wrote about allyship directly, connecting that idea to advocacy or action. Intercultural allyship is working across cultural differences in support of and in partnership with others (Sorrells, 2016, p. 260).

Acceptance, appreciation, and connection to culturally diverse people. Students wrote about how the final group project increased their acceptance and appreciation of and connection to culturally diverse people. Two students wrote about how the final group project helped them learn "how to accept different cultural identities and backgrounds" or to "not be afraid to accept and learn about different cultures." For some students, acceptance evolved into appreciation. One student explained: "I have learned to appreciate cultures better and I have also learned that when it comes to culture, I still do not know a lot and I should be open to learning more." Allyship must begin with acceptance and appreciation of culturally diverse groups, especially since many students come into this class without experience interacting with culturally diverse communities (Heinz, 2004).

Because many of the partnered co-cultural groups were international student organizations, some students wrote about how they have become more appreciative of the diversity of international students on campus. One student noted: "Now, I have an even-greater sense of appreciation for cultural events on campus through their role in increasing representation for minority groups in the community." The opportunity to connect with culturally diverse students was an important part of fostering allyship and wanting to show support for campus groups. Another student commented:

Being able to conduct an interview with a cultural organization on campus provided me with a very personal and honest way to connect with some members of a minority group and try to further my understanding of their personal and cultural values, beliefs, and worldviews.

This transformative learning transitioned directly into allyship for many students who wanted to support those organizations in the future.

Allyship through activism and action. For many students, the campus/community partnership evolved into allyship and wanting to take action or help others. One student described how "this [final group project] encouraged me to be allied with more international students on campus and it reshaped the way I look at the world." Another student connected this allyship to an awareness of their own privilege and the responsibility to assist others:

Journal of the Scholarship of Teaching and Learning, Vol. 21, No. 4, December 2021. josotl.indiana.edu 
Comparing the various aspects of my hybrid cultural identity has helped me to learn how to wield the power that my cultural identity holds and has shown me that I have a responsibility to use that power to help others.

Allyship included students aligning themselves with other cultural groups to assist those who might lack privilege. However, this version of allyship for students can be critiqued as performative White allyship, or allyship that does not involve the active dismantling of systemic inequities (Cross, 2021; Desnoyers-Colas, 2021; Hernández, 2020; Hesford, 2021).

Students also commented on how their allyship meant action or advocacy. One student explained that "this course has changed my complacency into a call for action." In one example of a call to action through allyship with culturally diverse groups, a student described: "Intercultural communication has been a class that has provoked a deeper level of contemplation as well as a call to self-awareness and action." Although students are referencing allyship through action in these examples, they are still focused on their own self-awareness rather than taking risks and advocating for systemic change (Cross, 2021; Desnoyers-Colas, 2021; Hernández, 2020). Partnering with campus co-cultural student groups allowed students the opportunity to develop allyship, increasing their understanding of other cultural groups and leveraging their own privilege to help others in order to "make a difference in the world." However, such allyship must be considered through a critical lens of performative White allyship, noting that students did not suggest engaging in advocacy that would dismantle systemic inequities.

\section{Curiosity About Other Cultures}

The final theme is curiosity about other cultures. This curiosity manifested in two ways: the desire to learn more, seek out interactions with culturally diverse groups, and travel; and being willing to ask questions of culturally diverse groups. Students' experiences interviewing members of campus cocultural student groups piqued their curiosity about other cultures.

Curiosity leading to learning more, seeking out other cultures, and travel. Students wrote about how the final group project put them in a position to interact with culturally diverse people, which created excitement for future interactions. A student noted: "This is not to say I was an exclusive person before, but I hardly went out of my way to experience other cultures. Now, I am excited to learn about other peoples' lives and their personal experiences." Students wrote about how these campus/community partnerships fostered curiosity. Another student described: "The biggest take away is to always be curious and never settle with the information that you have. When you are curious, you can learn so much more about yourself and the people around you." Conducting interviews with members of co-cultural student groups allowed students to learn about fellow students' personal experiences with diversity on campus, which encouraged students to learn more.

Students wrote about seeking out other cultures or supporting campus co-cultural student groups and cultural events. One student explained, "I am far more likely to search for these cultural spaces [of campus co-cultural student organizations] than I was before, and I feel like I can truly engage in what they have to offer." Indeed, because many students lacked direct experience interacting with people who are culturally diverse (Heinz, 2004), they wrote about how the final group project revealed the extensive cultural diversity on campus and their desire to seek out those groups.

Several students noted how the final group project increased their desire to attend campus cultural nights:

I've always wanted to go to one of the [student organizations'] cultural nights, but found it hard to find the time. The [final group project] presentations showed me that I really should

Journal of the Scholarship of Teaching and Learning, Vol. 21, No. 4, December 2021. josotl.indiana.edu 
try harder to make the time so that I can make more connections with other co-cultural groups on campus.

Because all class groups presented about intercultural communication in their partnerships to the rest of the class, everyone learned not only about their specific partnered co-cultural group but also about the rest of the class's co-cultural groups. Another student wrote: "I want to open the door to becoming more culturally aware by attending more multicultural events on campus." These campus/community partnerships piqued students' curiosity and led to them wanting to seek out other cultures and learning opportunities.

Students also wrote about a desire to travel. One student described specific cultures that they wanted to experience, including "Italian, Russian, Egyptian, and Japanese cultures," stating that they could "only root this newfound want [to travel] being from this class opening my mind out [sic] to other cultures." Another student commented: "I am excited to travel more now and learn about other cultures and languages so that I can communicate with people around the world." Interacting with campus co-cultural student groups was an experience that then created a desire to travel to other countries for some students, especially since many of the partnered groups were connected to other national cultures (e.g., International Relations Council, Indian Students' Association, Nepalese Students' Association, etc.).

Asking questions of culturally diverse people to learn about other cultures. Students also reflected on their curiosity about other cultures through asking questions. Sorrells (2016) used a framework of intercultural praxis, so we discussed the "inquiry" stage at length, which includes asking questions that are respectful of others through ethical intercultural communication. One student wrote about how they used this idea in their final group project: "Individuals [from our campus co-cultural student group] enjoy teaching others about their cultures and, as long as it is for the sake of gaining understanding and asked in a non-threatening way, questions are usually always welcome." Another student described how they used this framework: "We can use the tools [of intercultural praxis] to analyze a certain culture different from our own, and through curiosity and questioning, develop a more holistic understanding of the globalization affecting our world." Asking questions became a method to enact curiosity about other cultures through intercultural praxis. In sum, "One of the best ways to learn about another culture is to take the time to ask questions and be curious." Because students developed interview questions that were vetted by their instructor, they then had a positive experience using intercultural praxis and inquiry with their campus/community partnerships. In the last 5 years of teaching this course, I have never had the class groups or campus co-cultural student groups suggest that they had a negative experience in this semester-long partnership. This may be in part because of the deliberate scaffolding of the semester-long project, which includes many checkpoints to assess the use of ethical intercultural communication.

\section{Implications for Polarizing Pedagogy}

This case study addressed the question of how one might use civic engagement to foster campus/community relationships in this polarized era. I discussed one teaching solution that responds to the challenge of students' polarization across cultural differences in the class Intercultural Communication. By engaging in a structured, semester-long campus/community partnership between class groups and campus co-cultural student groups, students were able to practice intercultural competence and allyship, developing a desire to learn more and participate in other cultures on campus, in the community, and in the world. Students wrote about the importance of communicating across differences and developing a dialogue (Parker et al., 2011). They commented on the impact of personally connecting with culturally diverse fellow students, increasing their awareness of cultural

Journal of the Scholarship of Teaching and Learning, Vol. 21, No. 4, December 2021. josotl.indiana.edu 
diversity on campus and deepening their learning through culturally new learning processes (Chávez \& Longerbeam, 2016). However, students' use of allyship remained self-focused, reinforcing the critique of a performative White allyship that silently recognizes one's own privilege rather than boisterously taking risks to engage in systemic change (Cross, 2021; Desnoyers-Colas, 2021; Hernández, 2020; Hesford, 2021).

This assessment of the campus/community partnership in Intercultural Communication has practical implications. Depending on geographical context, this assignment could be used in other rural, land-grant public university settings, particularly if students are coming from communities where they have limited knowledge of or interaction with people from culturally diverse groups (Heinz, 2004). One limitation that limits the generalizability of this case study is that other PWIs might not have as robust a co-cultural student group population. If a university has a smaller number of cocultural student groups to choose from, those groups might face an undue burden of educating White students, reinforcing the critique of performative White allyship (Cross, 2021; Desnoyers-Colas, 2021; Hernández, 2020).

As intellectual diversity becomes more prominent in the national conversation about free speech and political affiliation in higher education (Ellis, 2019; FIRE, 2019; Hess, 2019), this assignment could be one way to strategically discuss controversial concepts such as power, privilege, and social justice (Cross, 2021). By applying the concepts in the semester-long assignment through communicating with co-cultural groups, students learn how to practice such concepts in personal and professional relationships. The use of intergroup dialogues such as these campus/community partnerships could be replicated outside the classroom within organizations and in the larger community. Two sections of students in this course benefitted from participating in a Difference is Dialogue campus/community intergroup dialogue program. Led by trained faculty, staff, and community facilitators, these students participated in 5 weeks of 1-hour dialogue sessions in small groups about controversial topics (e.g., intellectual diversity, feminism for today's college students, and gun violence in the United States). One student even contacted me after graduation to organize a similar Difference is Dialogue program in his hometown, given his new job in community development.

As universities continue to increase opportunities for U.S.-born students to interact with international or other culturally diverse students during their university education (Driskill, 2007; Kuehl \& Hungerford, 2017), this could be one assignment that could be used to meet such a goal, to deepen students' learning through culturally new learning processes (Chávez \& Longerbeam, 2016). Intercultural competence is a necessary skill to prepare students for careers and personal lives in which they will be communicating with people who are culturally diverse. By using civic engagement to enable students to communicate across differences through these structured campus/community partnerships, educators will be preparing such students for an increasingly diverse future.

\section{Appendix}

\section{Appendix 1. Intercultural Communication Final Group Project and Presentation Guidelines.}

Working with a group of four-five other people, choose a co-cultural group/space in the campus community that is different from the "mainstream" U.S. culture. Your topic (must first be approved by me) can be based on race/ethnicity (e.g., Latin American), religion (e.g., Islam), sexuality (e.g., LGBTQ), or some other facet of identity. Check out the list of campus co-cultural student organizations on Jacks Club Hub as a starting point.

Journal of the Scholarship of Teaching and Learning, Vol. 21, No. 4, December 2021. josotl.indiana.edu 
I will pass out anonymous peer review forms to each group member. You will be evaluated on your contributions to the group, equal burden of the workload, and quality of your work. Be sure you all agree upon individual responsibilities and define clear roles to easily determine what a fair distribution of work means for your project.

Creativity/ Audience Engagement (20\%)

Your project and presentation must be creative and impactful for your audience. Create a clearly identified "thesis" and clear main points so that the audience is able to recall the main ideas. Consider creative strategies to include active learning. Groups should incorporate 3-5 discussion questions that involve the audience.

Research/Interviews (20\%)

You must not only research this group/space (minimum of 10 scholarly, peer-reviewed sources in the communication discipline), but also visit it with your group members and conduct at least two interviews with members of that co-cultural group. You will turn in a draft of your interview guide on D2L Dropbox shortly after mid-semester; do not conduct interviews until you have received approval from the instructor. Your goal will be to find out about their history as a co-culture, their history as it's connected with the campus community, and most importantly, how they negotiate their identity in the community while trying to maintain cultural distinction. Additionally, consider how global issues impact this co-cultural group. Document your research through a references page (APA style). Document your fieldwork with photography, video, and/or audio. If interviews are not recorded, turn in a transcript of the questions and responses.

Intercultural Communication Concepts (20\%)

Be sure to incorporate at least 5 intercultural communication concepts that we have discussed in the course and apply them to your analysis of the co-cultural group. Sample concepts for analysis include: individualism/collectivism; power distance; short-term/long-term orientation; identity formations and power (analysis of age, gender, ethnicity, class, etc.), cultural identity and cultural space, non-verbal codes, etc.

Final Presentation (20\%)

You will present your research, interviews, and analysis of your selected co-cultural group/space in a 35-40-minute final research presentation that is coordinated so every group member speaks.

The presentation should proceed in three parts, with appropriate organization and delivery:

1) Explain your project and the research you've compiled about the co-cultural group/space (larger/global cultural history and cultural history connected to the campus community); 
2) Provide visual evidence of your interviews (show us your interview guide and responses or a video clip), creating an argument for how the group negotiates their identity in the campus community while trying to maintain unique aspects of their culture; and

3) Analyze the co-cultural group/space using concepts from this class, applying intercultural communication ideas and theories to the co-cultural group/space you have engaged this semester.

\section{References}

Braun, V., \& Clarke, V. (2006). Using thematic analysis in psychology. Qualitative Research in Psychology, 3(2), 77-101. https://doi.org/10.1191/1478088706qp063oa

Chávez, A. F., \& Longerbeam, S. D. (2016). Teaching across cultural strengths: A guide to balancing integrated and individuated cultural frameworks in college teaching. Stylus Publishing.

Cross, C. M. (2021). Intergroup dialogue: A pedagogical tool for continuous allyship for Black women. Women's Studies in Communication, 44(2), 151-155. https://doi.org/10.1080/07491409.2021.1923333

Desnoyers-Colas, E. F. (2021). The proof is in the hovering: Disrupting racism in white spaces. Women's Studies in Communication, 44(2), 138-141. https://doi.org/10.1080/07491409.2021.1923329

Driskill, G. W. (2007). Internationalizing the campus through an intercultural assignment. Communication Teacher, 21(1), 6-11. https://doi.org/10.1080/17404620701211485

Ellis, J. (2019, February 6). South Dakota lawmakers pass bill requiring intellectual diversity in colleges. Argus Leader. https://www.argusleader.com/story/news/2019/02/06/higher-edleaders-slam-free-speech-intellectual-diversity-bill/2790569002/

Foundation for Individual Rights in Education. (2019, December 18). Enacted campus free speech statutes-South Dakota. https://www.thefire.org/enacted-campus-free-speech-statutessouth-dakota/

Heinz, B. (2004). The world in one semester: International communication partners. Communication Teacher, 18(3), 87-90. https://doi.org/10.1080/1740462042000237909

Hernández, L. H. (2020). Silence, (in)action, and the downfalls of white allyship. Women \& Language, 43(1), 147-152. https://doi.org/10.34036/WL.2020.015

Hesford, W. S. (2021). Reading the signs: Performative white allyship. Quarterly Journal of Speech, 107(2), 239-244. https://doi.org/10.1080/00335630.2021.1915447

Hess, F. M. (2019, June 24). South Dakota's efforts to protect speech on campus could be a model for the nation. National Review. https://www.nationalreview.com/2019/06/south-dakotacampus-free-speech-protections/

Kuehl, R. A., Anderson, J., Drury, S. A. M., Holman, A., Hunt, C., \& Leighter, J. L. (2020). Creating a multidisciplinary dialogue about community-based participatory research partnerships of health and medicine. Rhetoric of Health \& Medicine, 3(1), 93-132. https://doi.org/10.5744/rhm.2020.1004

Kuehl, R. A., \& Hungerford, H. (2017). Global citizenship in intercultural communication: Spatial awareness of globalization through map your consumption. Communication Teacher, 31(4), 220-225. https://doi.org/10.1080/17404622.2017.1358388

Parker, P., Nemeroff, T., \& Kelleher, C. (2011). Training students to change their own campus culture through sustained dialogue. In K. E. Maxwell, B. A. Nagda, \& M. C. Thompson (Eds.), Facilitating intergroup dialogues: Bridging differences, catalyzing change (pp. 103-117). Stylus Publishing.

Journal of the Scholarship of Teaching and Learning, Vol. 21, No. 4, December 2021. josotl.indiana.edu 
Kuehl

Pew Research Center. (2019, December 17). In a politically polarized era, sharp divides in both partisan coalitions. Pew Research Center, U.S. Politics \& Policy.

https://www.pewresearch.org/politics/2019/12/17/in-a-politically-polarized-era-sharpdivides-in-both-partisan-coalitions/

Sorrells, K. (2016). Intercultural communication: Globalization and social justice (2nd ed.). SAGE Publications.

Journal of the Scholarship of Teaching and Learning, Vol. 21, No. 4, December 2021.

josotl.indiana.edu 